\title{
Coronary artery bypass grafting versus stents
}

\author{
JCR Iglézias*, A Chi, LFP Moreira, FB Jatene \\ From 23rd World Congress of the World Society of Cardio-Thoracic Surgeons \\ Split, Croatia. 12-15 September 2013
}

\section{Background}

Serruys P, et al [1] say that CABG is the procedure of choice for the treatment of patients with multivessel coronary artery disease resulting in lower rates of adverse clinical outcomes for cardiac and cerebrovascular diseases in the first year of follow-up. The study objectives were analyze the CABG versus stents and compare the samples studied, with respect to major cardiac outcomes.

\section{Methods}

Study of cohort type. We analyze 202 patients undergoing CABG in the service between 17/January and 31/ July/2009. The population was stratified being group G1 formed for 112 patients who received stents and group G2 formed for 90 patients undergoing to CABG. The software used was SPSS 15.0. The project was supported by FAPESP.

\section{Results}

We observe a higher percentage of female patients in G1-49 (24\%) versus $23(11 \%)-\mathrm{P}=0.007$ and found a higher percentage of diabetics in the G2-41 (20\%) versus $33(16 \%)-P=0.020$. There was a higher number of coronary vessels affected in G2 - $2.78 \pm 1.02$ versus $1.54 \pm$ $0.74-\mathrm{P}=0.001$ as for the number of grafts found that was higher in the group G2- $2.71 \pm 0.951$ versus $1.49 \pm$ $0.794-\mathrm{P}=0.001$. Of the 112 patients in G1, 72 (64.3\%) received only one stent. There was a higher incidence of hospitalizing due to cardiac causes in G1 - 11 (50\%) versus $3(14 \%)-\mathrm{P}=0.006$. In relation to the reappearance of angina it was higher for G1-12 (6\%) versus $2(1 \%)-\mathrm{P}=$ 0.022 . The hospital mortality was higher in G2-11 (5\%) versus $5(2 \%)-\mathrm{P}=0.064$.

\footnotetext{
* Correspondence: dcirossini@incor.usp.br

Cardiovascular Surgery Department, Heart Institute (InCor), Hospital das

Clínicas da Faculdade de Medicina da Universidade de São Paulo, São Paulo,
} Brazil

(c) 2013 Iglézias et al; licensee BioMed Central Ltd. This is an Open Access article distributed under the terms of the Creative Commons

\section{Conclusion}

We can state that CABG is the best procedure to treat patients with multivessel coronary disease, especially diabetics, since it allows significantly, a more complete revascularization, and decreases in the number of readmission due to cardiac causes; it reduces the recurrence of angina and improves quality of life after surgery, with similar hospital and late mortality.

Published: 11 September 2013

\section{Reference}

Surrey $P$, et al: Percutaneous Coronary Intervention versus CABG for Severe Coronary Artery Disease. N Eng J Med; 2009:360:961-971.

\section{doi:10.1186/1749-8090-8-S1-0181}

Cite this article as: Iglézias et al:: Coronary artery bypass grafting versus stents. Journal of Cardiothoracic Surgery 2013 8(Suppl 1):0181. and take full advantage of:

- Convenient online submission

- Thorough peer review

- No space constraints or color figure charges

- Immediate publication on acceptance

- Inclusion in PubMed, CAS, Scopus and Google Scholar

- Research which is freely available for redistribution 